\title{
World Alzheimer's Day: The Need to Spread Awareness
}

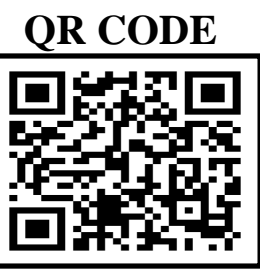

Dr. HARPREET GREWAL

Alzheimer's Disease (AD) is a type of neurodegenerative disease of the brain, just as Coronary Artery Disease (CAD) is a disease related to the heart. Due to its progressive nature, its symptoms worsen with time. AD is thought to begin 20 years or more before symptoms arise. ${ }^{1,2}$

It initiates itself as changes in the brain that are unnoticeable to the person affected. It is only after years of such changes that individuals experience noticeable symptoms such as memory loss and/or language problems. These symptoms occur due to the fact that the nerve cells (neurons) of the brain that are associated with thinking, learning and memory (cognitive function) have been damaged or destroyed beyond repair.

Its progression affects neurons in other parts of the brain and eventually, neurons responsible for a person to carry out basic bodily functions, such as walking and swallowing are affected. Individuals become bed-bound and require around-the-clock care and its ultimately leads to demise of the patient. ${ }^{3}$

\section{ALZHEIMER'S DISEASE OR DEMENTIA?}

It is common for people to wonder the difference between $\mathrm{AD}$ and dementia. The term "dementia" refers to an overall term for a particular group of symptoms and its characteristic symptoms include difficulties with memory, language, problem-solving and other thinking skills affecting a person's ability to perform routine day-to-day activities. In this context, $\mathrm{AD}$ is the most common cause of dementia. Infact, Alzheimer's dementia refers to dementia that is caused by, or believed to be caused due to the brain changes of a person suffering from Alzheimer's disease. Various studies have reported that episodic impairment of memory (amnesia) is prominently the earliest and most salient aspect of this AD dementia syndrome.
It has been estimated that by the year 2050, the number of people age 65 and older with AD in the USA alone is projected to reach 12.7 million. ${ }^{3}$ In India, there were an estimated 3.7 million people suffering from dementia in 2010 and the grim situation is that it is projected to rise to approximately 7.6 million by the year 2030 with its awareness remaining low throughout the country. ${ }^{4}$

Even within the field of medicine, research in dementia and related diseases remain low. Most of our existing knowledge and estimates of the incidence of dementia come from small regional case studies. ${ }^{4}$ There are, however, somewhat rare instances, particularly in younger patients (e.g., less than 65 years old), where AD initially presents with dementia dominated by higher-order visual dysfunction, executive dysfunction or deficits in language. The nature of $\mathrm{AD}$ is such that it may the prime cause of even more deaths than recognized and reported by official sources and the main reason for this is either its being considered as an "age" related change or inability to afford its treatment. AD is also a primal cause leading to disability as well as poor health among older adults as a person lives through years of morbidity as the disease progresses and till the time the patient dies. ${ }^{3}$

To raise awareness regarding this important disease, September $2 \mathbf{1}^{\text {st }}$ every year is World Alzheimer's Day around the world. This is an international campaign aimed at raising awareness and challenge the common stigma that surrounds Alzheimer related dementia.

September 2021 marks the $10^{\text {th }}$ world Alzheimer's month since the campaign was launched in 2012. From previous studies, an average of 2 out of 3 people globally have little or no understanding of Alzheimer's disease and associated dementia in their

(c) Dr. Harpreet Grewal. This is an open access article distributed under the terms of the Creative Commons Attribution License CC-BY-NC 4.0, which permits unrestricted use, distribution and reproduction in any medium, provided the use is not commercial and the original author(s) and source are cited. Submitted on: 05-Aug-2021; Accepted on: 27-Jul-2021 
countries. 5

\section{REFERENCES}

1. Quiroz YT, Zetterberg H, Reiman EM, Chen Y, Su Y, Fox-Fuller JT, et al. Plasma neurofilament light chain in the presenilin 1 E28oA autosomal dominant Alzheimer's disease kindred: A cross-sectional and longitudinal cohort study. Lancet Neuro 2020;19(6):513-21. https://doi.org/10.1016/S14744422(20)30137-X

2. Barthelemy N, Joseph-Mathurin N, Gordon BA, Hassenstab J, Benzinger TLS, et al. A soluble phosphorylated tau signature links tau, amyloid and the evolution of stages of dominantly inherited Alzheimer's disease. Nat Med 2020;26:398-407
3. Alzheimer's Association. Alzheimer's and Dementia. (Online Article). Available at: https://www.alz.org/alzheimers-dementia/factsfigures. [Last Accessed on $1^{\text {st }}$ July, 2021] 4. Brahma D. The persistence of memory: The burden of Alzheimer's disease in India. (Online Article). Available at: https://www.brookings.edu/blog/upfront/2019/o9/20/the-persistence-of-memory-theburden-of-alzheimers-disease-in-india/. [Last Accessed on $1^{\text {st }}$ July, 2021]

5. Bondi MW, Edmonds EC, Salmon DP. Alzheimer's Disease: Past, Present, and Future. J Int Neuropsychol Soc. 2017;23(9-10):818-31. https://doi.org/10.1017/S135561771700100X 